Author affiliations and support information (if applicable) appear at the end of this article.

Published at jco.org on October 26, 2017 T.R., K.J.S., and A.L.F. contributed equally to this work.

Corresponding author: Andrew L. Feldman, MD, Department of Laboratory Medicine and Pathology, Mayo Clinic, 200 First St SW, Rochester, MN 55905; e-mail: feldman.andrew@mayo.edu.

(C) 2017 by American Society of Clinical Oncology

0732-183X/17/3536w-4019w/\$20.00

\title{
International Assessment of Event-Free Survival at 24 Months and Subsequent Survival in Peripheral T-Cell Lymphoma
}

Matthew J. Maurer, Fredrik Ellin, Line Srour, Mats Jerkeman, N. Nora Bennani, Joseph M. Connors, Graham W. Slack, Karin E. Smedby, Stephen M. Ansell, Brian K. Link, James R. Cerhan, Thomas Relander, Kerry J. Savage, and Andrew L. Feldman

\section{$\begin{array}{llllllll}\text { A } & \text { B } & \text { S } & \text { T } & \text { R } & \text { A } & \text { C } & \text { T }\end{array}$}

\section{Purpose}

Peripheral T-cell lymphomas (PTCLs) have aggressive clinical behavior. We have previously shown that event-free survival (EFS) at 24 months (EFS24) is a clinically useful end point in diffuse large B-cell lymphoma. Here, we assess EFS24 and subsequent overall survival (OS) in large, multinational PTCL cohorts.

\section{Patients and Methods}

Patients with systemic PTCL newly diagnosed from 2000 to 2012 and treated with curative intent were included from the United States and Sweden (initial cohorts) and from Canada (replication cohort). EFS was defined as time from date of diagnosis to progression after primary treatment, retreatment, or death. Subsequent OS was measured after achieving EFS24 or from the time of progression if it occurred within 24 months. OS rates were compared with the age-, sex-, and country-matched general population.

\section{Results}

Seven hundred seventy-five patients were included in the study (the median age at diagnosis was 64 years; $63 \%$ were men). Results were similar in the initial and replication cohorts, and a combined analysis was undertaken. Sixty-four percent of patients progressed within the first 24 months and had a median OS of only 4.9 months (5-year OS, 11\%). In contrast, median OS after achieving EFS24 was not reached (5-year OS, 78\%), although relapses within 5 years of achieving EFS24 occurred in $23 \%$ of patients. Superior outcomes after achieving EFS24 were observed in younger patients ( $\leq 60$ years of age: 5 -year OS, 91\%).

\section{Conclusion}

EFS24 stratifies subsequent outcome in PTCL. Patients with PTCL with primary refractory disease or early relapse have extremely poor survival. However, more than one third of patients with PTCL remain in remission 2 years after diagnosis with encouraging subsequent OS, especially in younger patients. These marked differences in outcome suggest that EFS24 has utility for patient counseling, study design, and risk stratification in PTCL.

\section{J Clin Oncol 35:4019-4026. (C) 2017 by American Society of Clinical Oncology}

\section{INTRODUCTION}

Peripheral T-cell lymphomas (PTCLs) represents a group of non-Hodgkin lymphomas (NHLs) of mature T-cell origin with generally aggressive clinical behavior. ${ }^{1}$ PTCLs are less common than their B-cell counterparts, representing about $10 \%$ of NHLs in Western populations. Most systemic PTCLs are treated with anthracycline-based combination chemotherapy such as cyclophosphamide, doxorubicin, vincristine, and prednisone. This regimen was selected based on data from early trials that combined PTCLs with the more frequent aggressive B-cell NHLs, particularly diffuse large B-cell lymphoma (DLBCL). ${ }^{2}$ Although the regimen of cyclophosphamide, doxorubicin, vincristine, and prednisone remains an effective backbone for therapy of DLBCL, it is suboptimal for PTCL.

Although the WHO classification of lymphoid neoplasms lists $>25$ distinct mature T-cell and natural killer (NK) cell neoplasms, ${ }^{3}$ the three predominantly nodal subtypes that account for most systemic PTCLs in Western countries are PTCL not otherwise specified (NOS); angioimmunoblastic T-cell lymphoma (AITL); and anaplastic large-cell lymphoma (ALCL). Among 
ALCLs, approximately half are anaplastic lymphoma kinase (ALK) positive and have favorable overall survival (OS) rates in part, although not entirely, attributable to the young and generally healthy population in which this subtype occurs. ${ }^{4-6}$ Thus, PTCL NOS, AITL, and ALK-negative ALCL represent the majority of aggressive PTCLs. Some centers perform consolidative autologous stem-cell transplantation (SCT) in first remission, but its effect remains controversial, and only a fraction of patients achieve remission. Furthermore, identifying better drug regimens has been hampered by the overall rarity and heterogeneity of PTCLs coupled with a relative paucity of validated therapeutic targets for novel treatment approaches. Both of these issues are now being addressed, the first by developing consortium-based approaches ${ }^{7}$ and the second through better molecular understanding of PTCLs achieved by using next-generation sequencing and other high-throughput technologies. 8,9

We previously used landmark analyses based on eventfree survival (EFS) to evaluate clinically useful end points in other aggressively treated lymphomas and showed that EFS at 24 months (EFS24) stratified subsequent OS in DLBCL and immunochemotherapy-treated follicular lymphoma. ${ }^{10,11}$ In classic Hodgkin lymphoma (cHL), Hapgood et $\mathrm{al}^{12}$ have reported that achieving EFS24 predicts excellent outcome regardless of the status of established baseline prognostic factors. On the basis of these findings, we sought to evaluate EFS24 and OS in PTCL referenced to the general background population.

\section{PATIENTS AND METHODS}

\section{Study Design}

An international cohort of patients with newly diagnosed PTCL treated with curative-intent combination chemotherapy regimens was assembled from the University of Iowa/Mayo Clinic Specialized Program of Research Excellence Molecular Epidemiology Resource (MER) and the Swedish Lymphoma Registry (SWE). Subtypes included were ALKnegative ALCL; AITL; PTCL NOS; enteropathy-associated T-cell lymphoma; extranodal NK/T-cell lymphoma, nasal type; and hepatosplenic T-cell lymphoma. Precursor T-cell malignancies, primary cutaneous lymphomas, leukemic T-cell neoplasms, and ALK-positive ALCL were excluded. Demographic and clinical data were recorded, including International Prognostic Index (IPI) risk factors. To validate the findings and increase sample size for subset analyses, a replication cohort was assembled from the BC Cancer Agency (BCCA). After confirming initial results, the cohorts were pooled for subsequent analyses. This study was reviewed and approved by the Human Subjects Institutional Review Boards at Mayo Clinic and the University of Iowa; the Regional Ethical Board, Lund, Sweden; and the University of British Columbia-BCCA Research Ethics Board. Research was conducted in accordance with the Declaration of Helsinki.

\section{MER Cohort}

Patients were prospectively enrolled within 9 months of diagnosis in the MER cohort between 2002 and 2012. Details on the cohort have been previously published. ${ }^{13}$ All patients were $\geq 18$ years of age, were residents of the United States, and provided written consent. Exclusion criteria included known HIV infection and unwillingness or inability to provide written informed consent. Pathology was reviewed by an expert hematopathologist to verify diagnoses and WHO subtypes. Baseline clinical, laboratory, and treatment data were abstracted from medical records using a standard protocol. All patients were systematically contacted every
6 months for the first 3 years and then annually thereafter. Disease progression, retreatment, and deaths were verified through medical record review.

\section{Swedish Cohort}

Details on the Swedish cohort have been previously published. ${ }^{14}$ All patients in the Swedish Lymphoma Registry (SLR) diagnosed with T-cell lymphomas between January of 2000 and December of 2009 were identified. The SLR covers approximately $95 \%$ of all patients with lymphoma $\geq 18$ years of age in Sweden compared with the compulsory Swedish Cancer Registry, as described previously. The diagnosis of PTCL was established in routine clinical care with contributions from 21 pathology centers. Samples from approximately $75 \%$ of patients were reviewed by expert hematopathologists at large academic centers at diagnosis. Although specific pathology review of slides was not performed for this study, each pathology report was retrospectively reviewed for classification according to WHO criteria. ${ }^{15}$ Patients not fulfilling criteria for PTCL, as described earlier, were excluded. Response to treatment was most often assessed by review of computed tomography scan reports or, if missing or unavailable, review of physician notes. Data were collected from the SLR, and after informed consent, further data were obtained through medical record review.

\section{BCCA Cohort}

Patients $\geq 18$ years of age diagnosed between January of 2000 and January of 2012 with PTCL who met pathologic eligibility criteria and were treated with curative-intent chemotherapy were identified in the BCCA Lymphoid Cancer Database. Diagnoses were based on expert central BCCA hematopathology review. Patients were treated with anthracycline-based chemotherapy except for patients with hepatosplenic T-cell lymphoma (where nonanthracycline regimens were used and consolidative allogeneic transplantation was planned) and extranodal NK/T-cell lymphoma (where nonanthracyline regimens have been endorsed since 2010). In general, patients were observed every 3 months for 2 years, every 6 months until year 5 , and annually thereafter.

\section{Statistical Methods}

EFS was defined as the time from the date of pathologic diagnosis to progression after primary treatment, retreatment, or death from any cause. EFS24 was defined as being alive and event free 24 months after diagnosis. Subsequent OS was defined as time from achieving EFS24 (24 months after diagnosis) or time from progression in patients who did not achieve EFS24 (progression within 24 months of diagnosis) to death from any cause. OS was compared with the age-, sex-, and country-matched general population using rate tables from the United States, ${ }^{16}$ Sweden, ${ }^{16}$ and British Columbia ${ }^{17}$ via standardized mortality ratios (SMRs) and expected survival using a conditional approach via the survexp function in $\mathrm{R}$ (package survival), modified to allow country of origin as an additional matching feature in a multinational data set. Survival was plotted using KaplanMeier curves. $\chi^{2}$ and Wilcoxon rank sum tests were used to evaluate differences between patient characteristics across the cohorts. $P$ values were two-sided.

\section{RESULTS}

\section{Patient Characteristics}

Initial analyses were performed in 560 patients from the MER cohort $(n=138)$ and the SWE cohort $(n=422)$, with validation in 215 patients from the BCCA cohort. All 775 patients from the MER, SWE, and BCCA cohorts diagnosed with PTCL from 2000 to 2012 were included in the combined analysis. Cohort-specific and combined patient characteristics are listed in Table 1. Median age at 


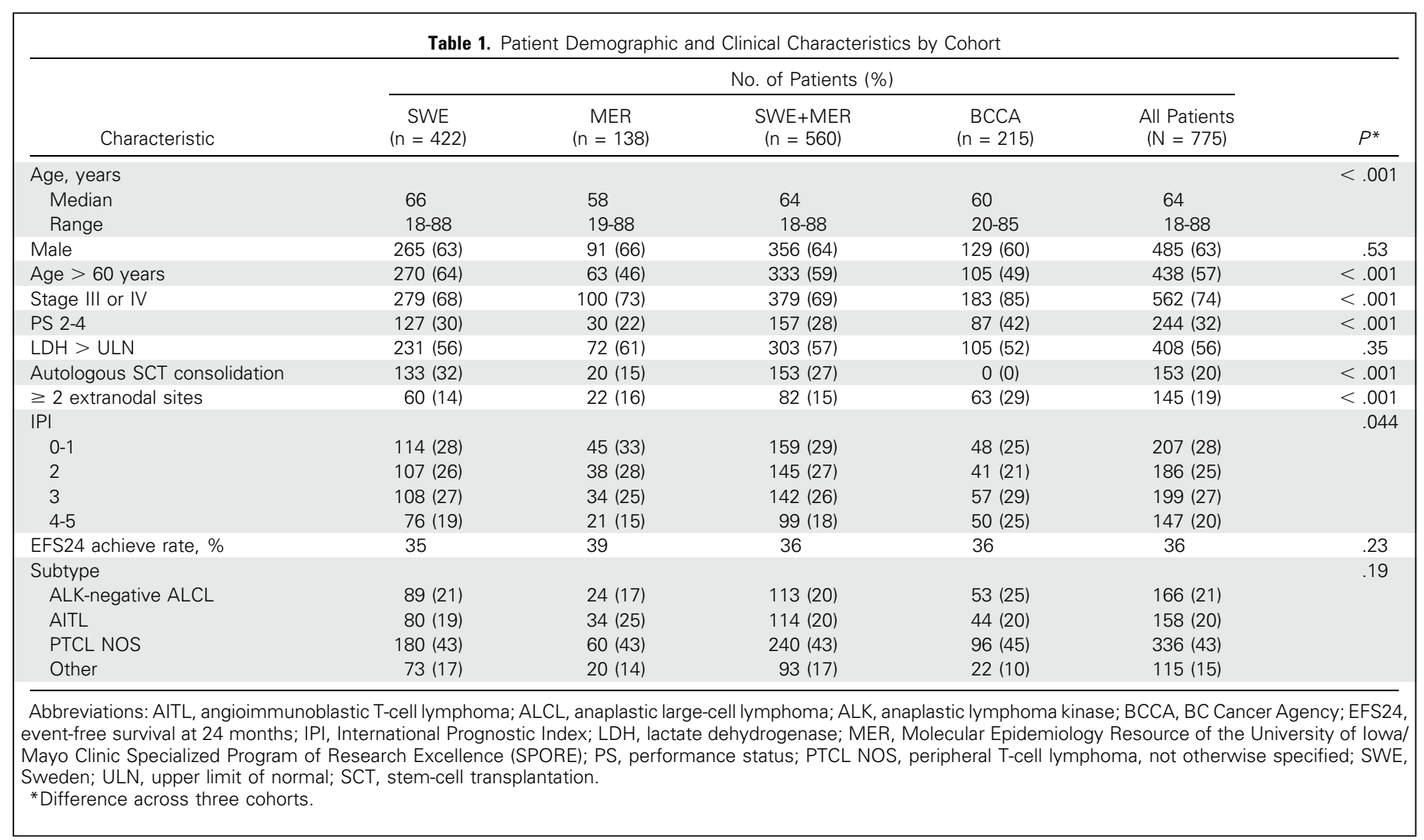

diagnosis was 64 years (range, 18 to 89 years), and 63\% of patients were male. Patients in the SWE cohort were older $(64 \%>60$ years old $v 46 \%$ in the MER cohort and $49 \%$ in the BCCA cohort; $P<$ $.001)$. Patients in the BCCA cohort had more advanced-stage disease (85\% stage III and IV $v 68 \%$ in the SWE cohort $v 73 \%$ in the MER cohort; $P<.001$ ), poorer performance status (PS; $42 \%$ with PS of 2 to 4 in the BCCA cohort $v 30 \%$ in the SWE cohort $v$ $22 \%$ in the MER cohort; $P<.001)$, and a higher frequency of IPI scores $>2(P=.044)$. Of the 775 patients, $736(95 \%)$ received anthracycline-based chemotherapy at diagnosis. Autologous SCT consolidation rates in first remission for the SWE cohort was 32\% versus $15 \%$ in the MER cohort, versus $15 \%$ in the BCCA cohort, $0 \%(P<.001)$. Median follow-up time was 59 months (range, 11 to 120 months) in the MER cohort, 97 months (range, 40 to 158 months) in the SWE cohort, and 117 months (range, 1 to 185 months) in the BCCA cohort. Across the 775 patients, 582 patients $(75 \%)$ had an event, and 516 patients (67\%) died. EFS and OS from diagnosis by cohort are shown in Appendix Figure A1 (online only).

\section{Initial Results by EFS24 in MER and SWE Cohorts and Validation in BCCA Cohort}

The initial analysis from the MER and SWE cohorts included 560 patients. Of these patients, 36\% achieved EFS24 and 64\% did not. Median OS after progression within the first 24 months was 5.3 months (95\% CI, 3.8 to 6.2 months), with a 5 -year OS of $10 \%$ and SMR of 44.7 (95\% CI, 39.4 to 50.6; Fig 1A). In contrast, median OS after achieving EFS24 was not reached, with a 5-year OS of $77 \%$ (95\% CI, 71\% to 84\%; Fig 1B). Expected 5-year OS was
$91 \%$ in the age-, sex-, and country-matched population (SMR, 3.40; $95 \%$ CI, 2.58 to 4.47; Table 2).

Because of the rarity of PTCL and the heterogeneity between outcomes in the MER and SWE cohorts (Appendix Fig A1), we enlisted a third cohort from the BCCA to confirm these results and increase sample size. The BCCA cohort included 215 patients. The findings were similar to those of the MER and SWE cohorts, with $36 \%$ of patients achieving EFS2 4 and $64 \%$ of patients not achieving EFS24. Median OS after progression within the first 24 months was 4.5 months (95\% CI, 2.2 to 5.7 months), with a 5-year OS of $14 \%$ and SMR of 50.3 (95\% CI, 42.1 to 60.1 ; Fig 1C). Median OS after achieving EFS24 was not reached, with a 5-year OS of $81 \%(95 \%$ CI, $73 \%$ to $91 \%$; Fig 1D). Expected 5-year OS was $92 \%$ in the age-, sex-, and country-matched population (SMR, 2.72; 95\% CI, 1.79 to 4.13 ; Table 2).

\section{Outcomes in Combined Cohort}

In the combined cohort analysis, $36 \%$ of patients achieved EFS24 and $64 \%$ of patients did not. Median OS after progression within the first 24 months was 4.9 months (95\% CI, 3.8 to 5.9 months), with a 5 -year OS of $11 \%$ and SMR of 46.4 (95\% CI, 41.8 to 51.3 ; Fig 2A). In contrast, median OS after achieving EFS24 was not reached, with a 5 -year OS of $78 \%$ (95\% CI, $73 \%$ to $84 \%$; Fig 2B). Expected 5-year OS was $92 \%$ in the age-, sex-, and country-matched population (SMR, 3.16; 95\% CI, 2.48 to 3.98 ; Table 2). In patients who achieved EFS24, the 5-year risk of subsequent lymphoma relapse was 23\% (Fig 3A), and survival after late relapse was poor, with a median OS of 10.3 months $(95 \% \mathrm{CI}$, 5.7 to 19.1 months; Fig 3B). 

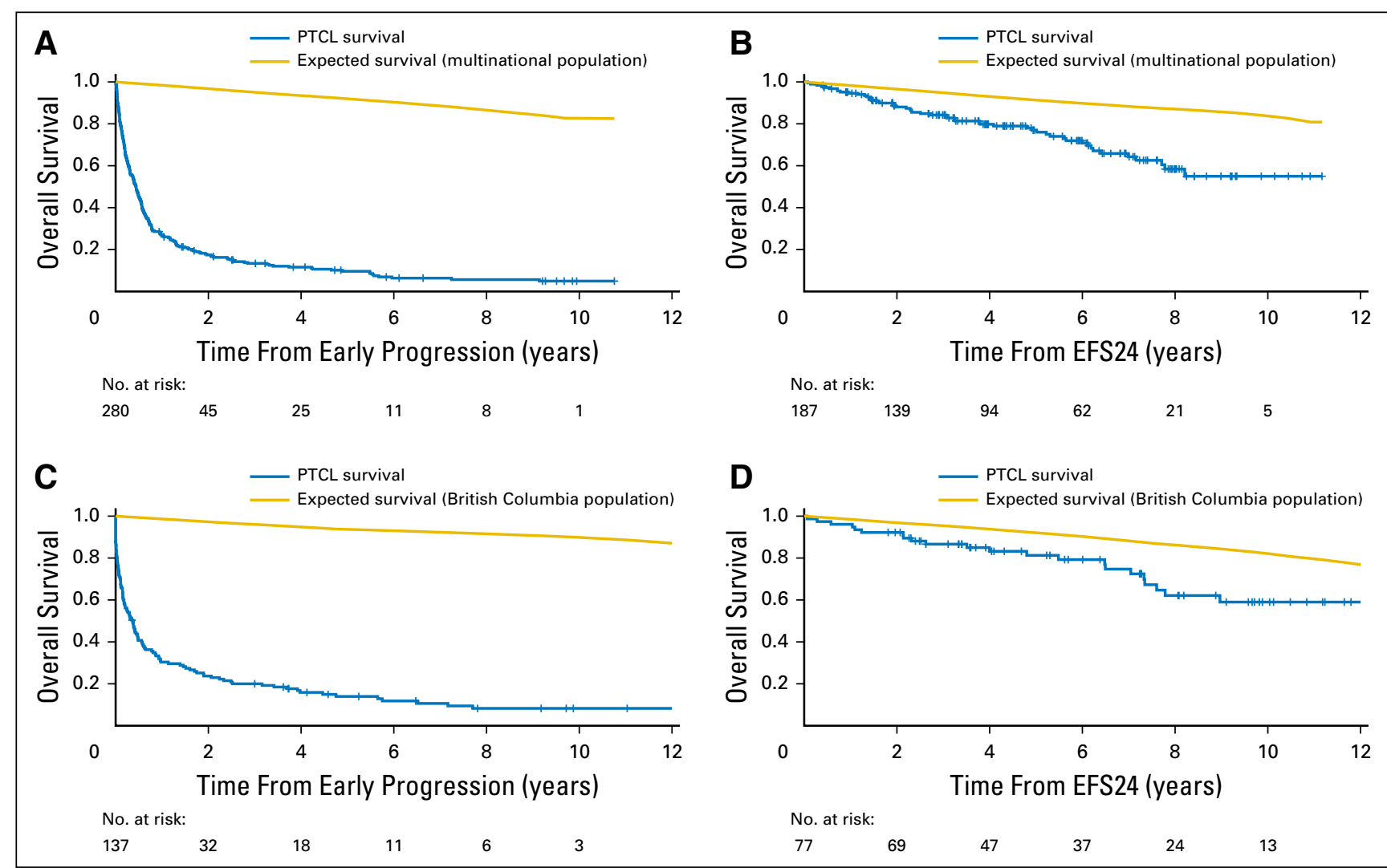

Fig 1. Overall survival (OS) based on 24-month event-free survival (EFS24) in initial and replication cohorts. (A) Subsequent OS of patients who did not achieve EFS24 (progression within 24 months after diagnosis) in the Molecular Epidemiology Resource (MER) and Sweden (SWE). (B) Subsequent OS of patients who achieved EFS24 in the MER and SWE cohorts. (C) Subsequent OS of patients who did not achieve EFS24 in the British Columbia Cancer Agency (BCCA) replication cohort. (D) Subsequent OS of patients who achieved EFS24 in the BCCA cohort. PTCL, peripheral T-cell lymphoma.

\section{Outcomes by Pathologic Subtype and Other Subgroups in Combined Cohort}

This study limited subtypes to the aggressive PTCLs, mirroring criteria often used for clinical trials. ${ }^{18}$ However, even aggressive PTCL subtypes differ in clinical outcomes ${ }^{4}$; therefore, we examined subtypespecific outcomes based on EFS24. In general, OS rates compared with the background population after achieving EFS24 were similar by subtype (Fig 4; Table 2). Of note, although ALK-negative ALCL had the best EFS and OS from diagnosis among the subtypes studied (Appendix Fig A2, online only), it had the poorest subsequent 5-year OS after achieving EFS24 (69\%, compared with 78\% for PTCL NOS, $84 \%$ for AITL, and 93\% for other subtypes; Fig 4).

The most favorable outcomes after achieving EFS24 were observed in younger patients, defined as age $\leq 60$ years based on the IPI ( $\mathrm{n}=137$; 5 -year OS of $91 \% v 98 \%$ expected; Appendix Fig A3A, online only). Patients who received autologous SCT in first remission $(\mathrm{n}=72)$ had a 5 -year OS of $88 \%$ ( $v 96 \%$ expected); patients who did not receive autologous SCT who achieved EFS24 $(\mathrm{n}=189)$ had a 5 -year OS of $74 \%$ ( $v 90 \%$ expected; Appendix Fig A3B). It is important to note, however, that this study was neither designed nor powered to address the question of whether patients with PTCL derive benefit from SCT in first remission. Additional factors (eg, comorbidities) may also affect this analysis. Table 2 lists outcomes based on other clinical factors. EFS24 status was informative for future OS in all patient subsets and superseded prognostic classification at diagnosis.

\section{Sensitivity Analysis for EFS24 Versus Other Time Points}

As a sensitivity analysis, we examined outcomes in the pooled data set by other landmark time points of EFS, including EFS at 12, $18,30,36$, and 48 months. Although subsequent 5 -year OS continued to increase from the 12-month EFS time point (67\%) to the EFS24 time point (78\%), there was little benefit to examining later EFS time points and no meaningful narrowing of the difference between the EFS-based OS and the expected OS (Appendix Table $\mathrm{A} 1$, online only). There was little difference in subsequent outcomes after progression regardless of the time point chosen (5-year OS after progression, $10.6 \%$ for 12 months $v 12.2 \%$ for 36 months; Appendix Table A2, online only).

\section{DISCUSSION}

To our knowledge, this study is the first to examine EFS-based end points systematically in patients with aggressive subtypes of PTCL treated with anthracycline-based chemotherapy regimens. The data demonstrate that even in this group of patients with generally poor prognosis, those who remain event free 2 years after diagnosis have favorable long-term outcomes, with some patients potentially cured. Conversely, events within 2 years are associated with early death in nearly all patients. Thus, EFS24 is a dichotomous end point that allows individualized risk prediction in patients with PTCL and can help inform patient counseling, 
Table 2. Outcomes Based on Failing or Achieving EFS24

\begin{tabular}{|c|c|c|c|c|c|c|c|c|c|}
\hline \multirow[b]{2}{*}{ Subset } & \multicolumn{3}{|c|}{ Outcomes From Time of Diagnosis } & \multicolumn{3}{|c|}{$\begin{array}{l}\text { Outcomes From Time of Progression Within } \\
24 \text { Months (no achievement of EFS24) }\end{array}$} & \multicolumn{3}{|c|}{$\begin{array}{l}\text { Outcomes From Time of Achieving } \\
\text { EFS24 }\end{array}$} \\
\hline & No. of Patients & SMR (95\% Cl) & $\begin{array}{c}\text { 5-Year OS } \\
\text { From } \\
\text { Diagnosis } \\
(\%)\end{array}$ & $\begin{array}{l}\text { No. of } \\
\text { Patients }\end{array}$ & SMR $(95 \% \mathrm{Cl})$ & $\begin{array}{l}\text { 3-Year OS } \\
\text { From } \\
\text { Progression } \\
(\%)\end{array}$ & $\begin{array}{l}\text { No. of } \\
\text { Patients }\end{array}$ & SMR $(95 \% \mathrm{Cl})$ & $\begin{array}{c}\text { 3-Year } \\
\text { OS } \\
\text { From } \\
\text { EFS24 } \\
(\%)^{*}\end{array}$ \\
\hline All & 775 & 11.5 (10.5 to 12.5$)$ & 37.9 & 492 & 46.4 (41.9 to 51.3$)$ & 16.2 & 264 & 3.16 (2.48 to 3.98$)$ & 85.0 \\
\hline \multicolumn{10}{|l|}{ Age, years } \\
\hline$>60$ & 438 & 8.84 (7.95 to 9.83 ) & 28.2 & 305 & 33.6 (29.5 to 38.3 ) & 12.5 & 127 & 2.71 (2.06 to 3.55 ) & 77.2 \\
\hline \multicolumn{10}{|l|}{ Sex } \\
\hline Male & 485 & $10.8(9.75$ to 12.1$)$ & 37.3 & 307 & 56.1 (49.4 to 63.7$)$ & 12.7 & 162 & 3.13 (2.37 to 4.12 ) & 85.0 \\
\hline Female & 290 & 12.8 (11.1 to 14.7$)$ & 39.1 & 185 & 35.9 (30.5 to 42.4$)$ & 22.1 & 102 & 3.24 (2.06 to 4.87 ) & 84.9 \\
\hline \multicolumn{10}{|l|}{ Stage } \\
\hline $\mid / / 1$ & 202 & 7.19 (5.95 to 8.68$)$ & 53.6 & 91 & 61.7 (48.6 to 78.2 ) & 15.2 & 105 & 2.58 (1.65 to 3.84$)$ & 87.5 \\
\hline III/IV & 562 & 13.5 (12.3 to 14.9$)$ & 28.6 & 393 & 44.4 (39.6 to 49.6 ) & 16.2 & 156 & 3.57 (2.70 to 4.73$)$ & 83.1 \\
\hline $0-1$ & 521 & 9.20 (8.25 to 10.3$)$ & 45.2 & 293 & 42.1 (37.0 to 47.8 ) & 19.1 & 212 & 3.02 (2.32 to 3.93 ) & 85.8 \\
\hline $2-4$ & 244 & 16.6 (14.8 to 18.6 ) & 24.3 & 191 & 67.7 (57.2 to 80.2 ) & 10.5 & 50 & 3.77 (2.38 to 5.99$)$ & 81.2 \\
\hline \multicolumn{10}{|l|}{$\mid \mathrm{PI}$} \\
\hline $0-1$ & 207 & 7.18 (5.88 to 8.76$)$ & 60.2 & 86 & 52.7 (41.5 to 66.9 ) & 21.9 & 114 & 2.65 (1.74 to 4.02 ) & 88.5 \\
\hline $2-3$ & 385 & 12.1 (10.8 to 13.7$)$ & 34.4 & 258 & 45.3 (39.4 to 52.0 ) & 17.3 & 115 & 3.44 (2.48 to 477$)$ & 83.4 \\
\hline $4-5$ & 147 & 17.7 (14.8 to 21.0$)$ & 17.8 & 119 & 52.4 (42.6 to 64.7$)$ & 7.9 & 28 & $4.20(2.44$ to 7.23$)$ & 73.3 \\
\hline $\begin{array}{l}\text { Autologous SCT } \\
\text { consolidation }\end{array}$ & NA & NA & NA & 74 & $148(115$ to 191$)$ & 11.8 & 72 & 4.11 (2.39 to 7.09 ) & 92.8 \\
\hline \multicolumn{10}{|l|}{ Subtype } \\
\hline PTCL NOS & 336 & 11.0 (9.66 to 12.5$)$ & 37.9 & 222 & 34.4 (29.7 to 39.9 ) & 19.4 & 102 & 3.11 (2.16 to 4.47$)$ & 84.6 \\
\hline AITL & 158 & $10.0(8.30$ to 12.1$)$ & 35.0 & 107 & $63.8(51.5$ to 79.0$)$ & 13.3 & 50 & $2.19(1.30$ to 3.69$)$ & 89.4 \\
\hline $\begin{array}{l}\text { ALK-negative } \\
\text { ALCL }\end{array}$ & 166 & 10.5 (8.60 to 12.7$)$ & 44.7 & 86 & 44.0 (34.3 to 56.5$)$ & 20.9 & 77 & 4.68 (3.14 to 6.98 ) & 78.7 \\
\hline Other PTCL & 115 & 21.2 (17.1 to 26.3 ) & 32.4 & 77 & 184 (141 to 240$)$ & 4.8 & 35 & 2.71 (1.22 to 6.03 ) & 93.2 \\
\hline
\end{tabular}

Abbreviations: AITL, angioimmunoblastic T-cell lymphoma; ALCL, anaplastic large-cell lymphoma; ALK, anaplastic lymphoma kinase; BCCA, BC Cancer Agency; ECOG, Eastern Cooperative Oncology Group; EFS24, event-free survival at 24 months; IPI, International Prognostic Index; LDH, lactate dehydrogenase; MER, Molecular Epidemiology Resource of the University of lowa/Mayo Clinic Specialized Program of Research Excellence (SPORE); NOS, not otherwise specified; OS, overall survival; PS, performance status; PTCL, peripheral T-cell lymphoma; SCT, stem-cell transplantation; SMR, standardized mortality ratio; SWE, Sweden; ULN, upper limit of normal. * Total of 5 years after diagnosis.

biomarker discovery, clinical trial design, and precision medicine approaches.

Nearly two thirds of the 775 patients in this international cohort developed progressive disease within 24 months of diagnosis, confirming the aggressive nature of the PTCL subtypes included and the relative ineffectiveness of current chemotherapy regimens. The subsequent 5-year OS rate after progression in these patients was only $11 \%$, indicating that few patients with early progression can be treated successfully with salvage therapy, consistent with the results of a previous BCCA-based study by Mak et $\mathrm{al}^{19}$ of relapsed or progressive PTCL. With somewhat different inclusion criteria, they reported a median time to event of 6.7 months, with median progression-free survival and OS times after relapse or progression of 3.1 months and 5.5 months, respectively. ${ }^{19}$ However, despite the overall poor prognosis of PTCL, $36 \%$ of patients in the current study achieved EFS24, with a subsequent 5 -year OS of $78 \%$. This finding underscores that a subset of patients with typically aggressive PTCL subtypes has favorable outcomes. Mak et $\mathrm{al}^{19}$ also identified occasional longterm survivors after relapse, particularly in patients with good PS scores. In the current analysis, patients with a PS of 2 to 4 had a 5 -year OS rate of 76\% after achieving EFS24; even patients with IPI scores of 4 or 5 at diagnosis had a subsequent 5 -year OS rate of $59 \%$. Subsequent OS rates after achieving EFS24 were $>90 \%$ in patients $\leq 60$ years of age and those who received autologous SCT, suggesting that EFS24 may be a particularly important end point in these patients. Notably, EFS24 status stratified subsequent OS across all subtypes and diagnostic prognosis groups. For the practicing clinician, the EFS24 status allows recalibration of a patient's prognosis after the patient has been treated and observed for 2 years since diagnosis.

Even within distinct subtypes of aggressive PTCLs, molecular heterogeneity has important implications for outcome. Genetic stratification of ALK-negative ALCL using clinically available fluorescence in situ hybridization tests yields subgroups of patients with 5-year OS rates ranging from $17 \%$ for patients with TP63 


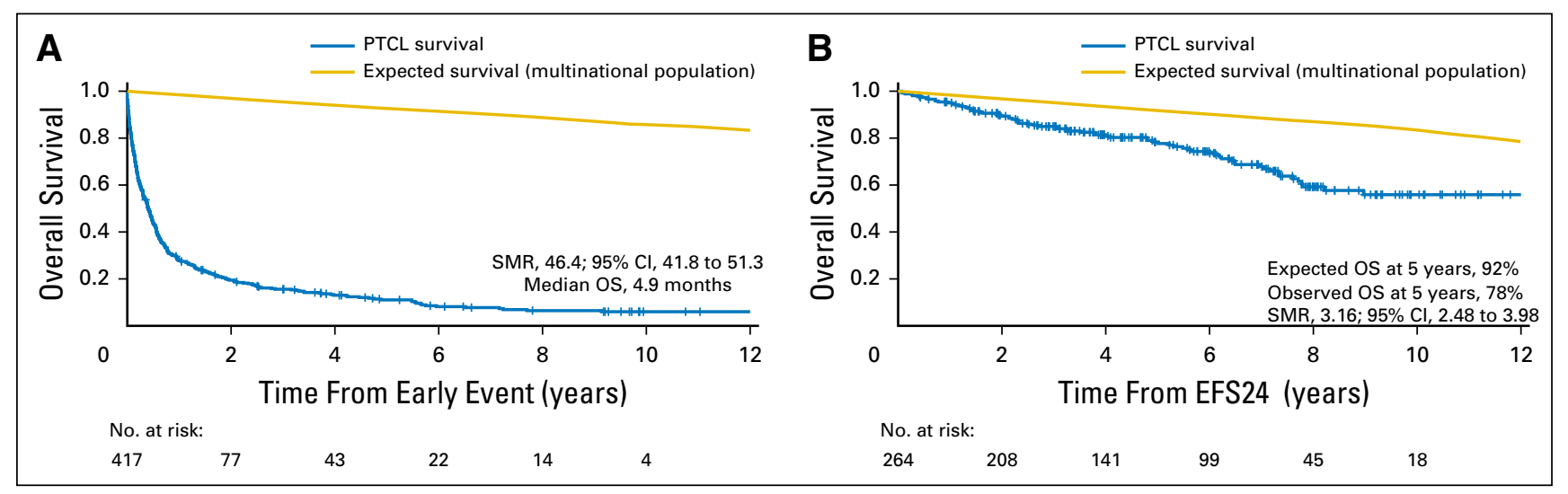

Fig 2. Overall survival (OS) based on 24-month event-free survival (EFS24) in combined cohorts $(n=775)$. (A) Subsequent OS of patients who did not achieve EFS24. (B) Subsequent OS of patients who achieved EFS24. SMR, standardized mortality ratio.

rearrangements to $90 \%$ for those with DUSP22 rearrangements (similar to ALK-positive ALCL). ${ }^{20,21}$ Therefore, future genetic stratification of the ALK-negative ALCL cohort might improve utility of EFS24 in this disease and elucidate the clinical significance of late events. Within PTCL NOS, prognostically distinct subgroups can be delineated based on expression of the transcription factors GATA3 and TBX21. ${ }^{9,22}$ Furthermore, a markedly heterogeneous spectrum of mutations in all subtypes affects a variety of processes including $\mathrm{T}$-cell receptor signaling, communication between tumor cells and the microenvironment, and key growth signals. ${ }^{8,23,24}$ The use of a dichotomous end point that allows individualized risk prediction is particularly important in rare diseases such as PTCL, where limited numbers of patients may make formal surrogate end point analysis difficult. We recently developed a personalized risk prediction tool for DLBCL that estimates the probability of failing to achieve EFS24 using a multivariable model that includes standard IPI criteria. ${ }^{25}$ This model outperformed IPI and National Comprehensive Cancer Network IPI and is easily accessible through app-based electronic tools. The current findings on the discriminatory value of EFS24 in PTCL provide the opportunity for developing a similar tool for this group of diseases.
Although achieving EFS24 identifies patients with PTCL with relatively favorable subsequent outcomes, survival does not reach that of the general population, and SMRs remain significantly worse than for other lymphomas studied, including DLBCL, aggressively treated follicular lymphoma, and cHL. ${ }^{10-12}$ Notably, patients who achieve EFS24 remain at a high risk of late progression (23\% at 5 years from achieving EFS24, approximately three times the rate reported in DLBCL ${ }^{10,26}$ and $\mathrm{CHL}^{12}$ ). Furthermore, survival after late progression of PTCL was nearly as poor as survival after early progression; thus, improved therapies are needed across all PTCLs. ${ }^{1}$ Future early-phase clinical trials could use EFS24 as a surrogate end point to speed assessment of novel drugs and combinations. Despite outcomes not reaching the general population level, results are encouraging in patients achieving EFS24, and some patients seem to be cured. Because most outcomes data do not include the long follow-up obtained in the prospective cohorts studied here, EFS24 may represent a useful end point for discovery and validation of predictive biomarkers that can inform decisions regarding the intensity and selection of therapy in individual patients. ${ }^{27}$

Strengths of the study include the large data set of patients for an uncommon disease and consistent results across multiple

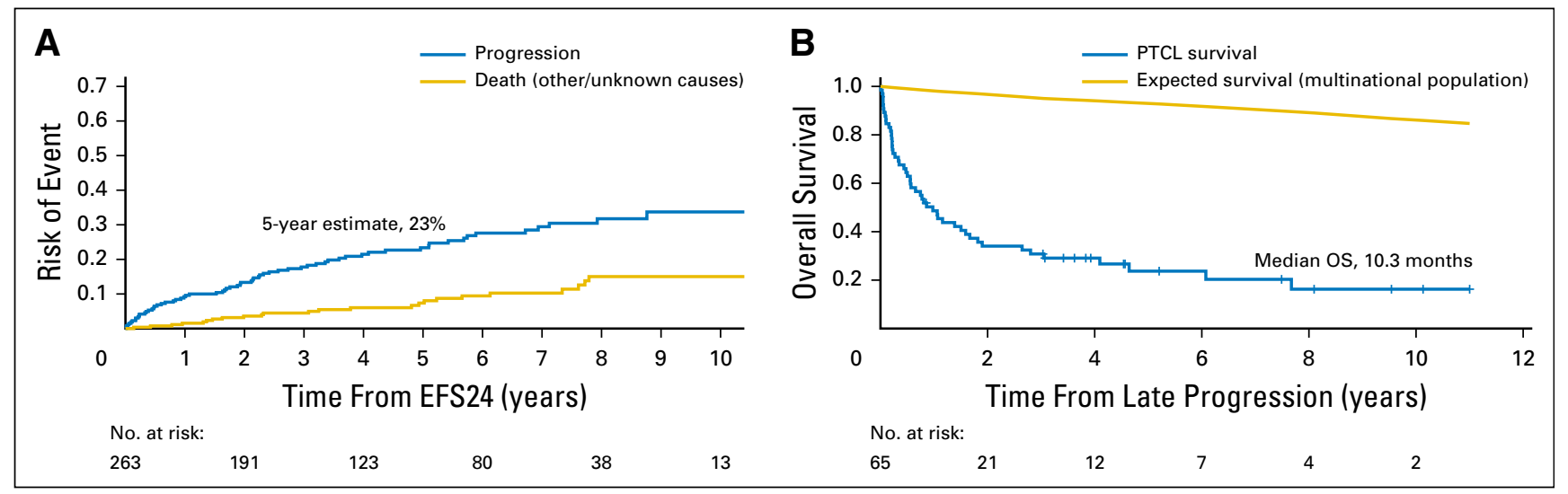

Fig 3. Disease relapse in patients with peripheral T-cell lymphoma (PTCL) after achieving 24-month event-free survival (EFS24). (A) Estimated 5-year cumulative incidence of relapse or progression after achieving EFS24. The competing risk of death as a result of other or unknown causes is also shown. (B) Subsequent overall survival (OS) after relapse after initially achieving EFS24. 

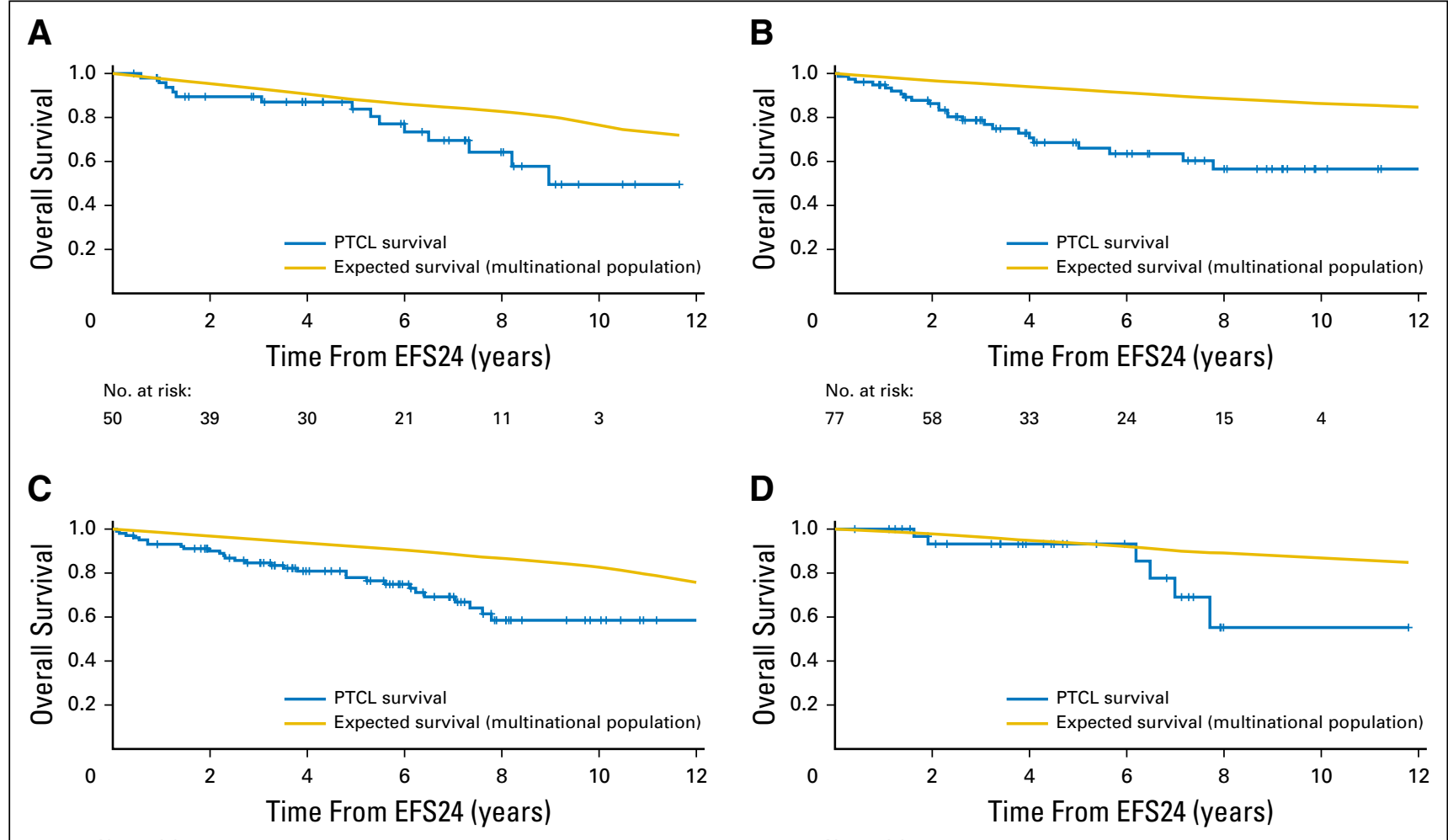

No. at risk:

$\begin{array}{llllll}102 & 84 & 59 & 42 & 18 & 10\end{array}$

D

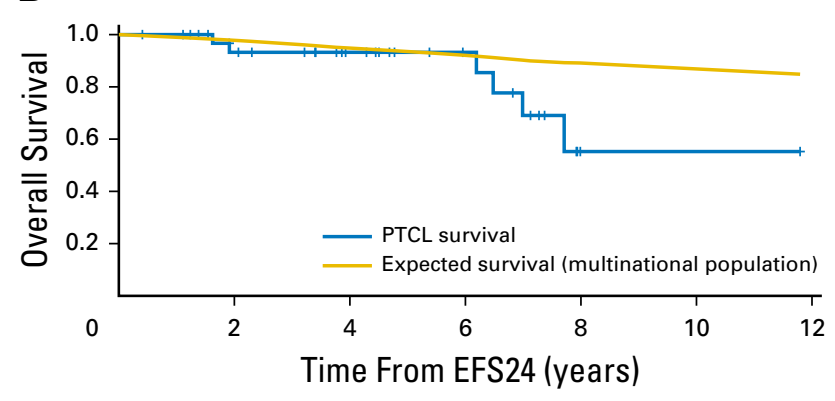

No. at risk:

$\begin{array}{llllll}35 & 27 & 19 & 12 & 1 & 1\end{array}$

Fig 4. Subsequent overall survival after achieving 24-month event-free survival (EFS24) stratified by the following pathologic subtypes: (A) angioimmunoblastic T-cell

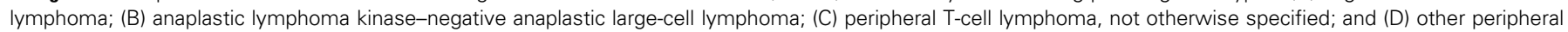
T-cell lymphoma subtypes.

international registry-based cohorts. The data are quite mature, with a median follow-up time from diagnosis of $>6$ years and complete follow-up on nearly $70 \%$ of patients. However, although large for this disease, the sample size is small for subgroup analyses; predictions of outcomes for PTCL subtypes and other subgroups should be confirmed in other studies. The 24-month time point was chosen as a result of prior results in DLBCL, cHL, and immunochemotherapy-treated follicular lymphoma. ${ }^{10-12}$ Examining a range of time points from 12 to 48 months suggested there was little to be gained from later end points that take longer to evaluate, whereas earlier end points did not dichotomize the two groups as effectively.

In conclusion, assessment of EFS24 stratifies subsequent outcome in PTCL. Patients with early relapse of PTCL have extremely poor subsequent survival. However, more than one third of patients with PTCL remain in remission 2 years from diagnosis after initial chemotherapy and have encouraging OS rates, although survival remains significantly worse than the matched general population and risk of subsequent progression persists. Such patients require indefinite surveillance with diligent evaluation of suspicious clinical findings; the role of radiologic surveillance merits further study. Subset analysis suggests that younger patients ( $\leq 60$ years of age) have a better prognosis, although survival remains inferior to that expected in the background population. The marked differences in OS in patients with PTCL who did and did not achieve EFS24 suggest that this end point may be useful for patient counseling and as an end point to assess novel biomarkers for risk stratification.

\section{AUTHORS' DISCLOSURES OF POTENTIAL CONFLICTS OF INTEREST}

Disclosures provided by the authors are available with this article at jco.org.

\section{AUTHOR CONTRIBUTIONS}

Conception and design: Matthew J. Maurer, Fredrik Ellin, Mats Jerkeman, James R. Cerhan, Thomas Relander, Kerry J. Savage, Andrew L. Feldman Provision of study materials or patients: Brian K. Link, Thomas Relander Collection and assembly of data: Matthew J. Maurer, Fredrik Ellin, Line Srour, Joseph M. Connors, Graham W. Slack, Karin E. Smedby, Stephen M. Ansell, Brian K. Link, James R. Cerhan, Thomas Relander, Kerry J. Savage, Andrew L. Feldman

Data analysis and interpretation: Matthew J. Maurer, Fredrik Ellin, Line Srour, N. Nora Bennani, Joseph M. Connors, Karin E. Smedby, Stephen M. Ansell, James R. Cerhan, Kerry J. Savage, Andrew L. Feldman

Manuscript writing: All authors

Final approval of manuscript: All authors

Accountable for all aspects of the work: All authors 


\section{REFERENCES}

1. Armitage JO: The aggressive peripheral T-cell lymphomas: 2015. Am J Hematol 90:665-673, 2015

2. Fisher RI, Gaynor ER, Dahlberg S, et al: A phase III comparison of CHOP vs. m-BACOD vs. ProMACE-CytaBOM vs. MACOP-B in patients with intermediate- or high-grade non-Hodgkin's lymphoma: Results of SWOG-8516 (Intergroup 0067), the National High-Priority Lymphoma Study. Ann Oncol 5: 91-95, 1994 (suppl 2)

3. Swerdlow SH, Campo E, Pileri SA, et al: The 2016 revision of the World Health Organization classification of lymphoid neoplasms. Blood 127:2375-2390, 2016

4. Vose J, Armitage J, Weisenburger $D$, et al: International peripheral T-cell and natural killer/T-cell lymphoma study: Pathology findings and clinical outcomes. J Clin Oncol 26:4124-4130, 2008

5. Savage KJ, Harris NL, Vose JM, et al: ALKanaplastic large-cell lymphoma is clinically and immunophenotypically different from both ALK+ ALCL and peripheral T-cell lymphoma, not otherwise specified: Report from the International Peripheral T-Cell Lymphoma Project. Blood 111:5496-5504, 2008

6. Gascoyne RD, Aoun P, Wu D, et al: Prognostic significance of anaplastic lymphoma kinase (ALK) protein expression in adults with anaplastic large cell lymphoma. Blood 93:3913-3921, 1999

7. Advani RH, Ansell SM, Lechowicz MJ, et al: A phase II study of cyclophosphamide, etoposide, vincristine and prednisone (CEOP) alternating with pralatrexate $(P)$ as front line therapy for patients with peripheral T-cell lymphoma (PTCL): Final results from the T-cell consortium trial. Br J Haematol 172:535-544, 2016

8. Sakata-Yanagimoto $M$, Chiba S: Molecular pathogenesis of peripheral $T$ cell lymphoma. Curr Hematol Malig Rep 10:429-437, 2015
9. Iqbal J, Wright G, Wang C, et al: Gene expression signatures delineate biological and prognostic subgroups in peripheral T-cell lymphoma. Blood 123:2915-2923, 2014

10. Maurer MJ, Ghesquières $H$, Jais JP, et al: Event-free survival at 24 months is a robust end point for disease-related outcome in diffuse large B-cell lymphoma treated with immunochemotherapy. J Clin Oncol 32:1066-1073, 2014

11. Maurer MJ, Bachy $E$, Ghesquières $H$, et al: Early event status informs subsequent outcome in newly diagnosed follicular lymphoma. Am J Hematol 91:1096-1101, 2016

12. Hapgood G, Zheng Y, Sehn LH, et al: Evaluation of the risk of relapse in classical Hodgkin lymphoma at event-free survival time points and survival comparison with the general population in British Columbia. J Clin Oncol 34:2493-2500, 2016

13. Drake MT, Maurer MJ, Link BK, et al: Vitamin $D$ insufficiency and prognosis in non-Hodgkin's lymphoma. J Clin Oncol 28:4191-4198, 2010

14. Ellin $F$, Landström $J$, Jerkeman $M$, et al: Realworld data on prognostic factors and treatment in peripheral T-cell lymphomas: A study from the Swedish Lymphoma Registry. Blood 124:1570-1577, 2014

15. Swerdlow SH, Campo E, Harris NL, et al (eds): WHO Classification of Tumours of Haematopoietic and Lymphoid Tissues, Fourth Edition. IARC, Lyon, France. 2008

16. The Human Mortality Database: Homepage. http://www.mortality.org/

17. Statistics Canada: Life Tables, Canada, provinces and territories. http://www5.statcan.gc.ca/olc-cel/olc. action?objld $=84-537-X \&$ \&objType $=2 \&$ lang $=$ en\&limit $=0$

18. d'Amore F, Relander T, Lauritzsen GF, et al: Up-front autologous stem-cell transplantation in peripheral T-cell lymphoma: NLG-T-01. J Clin Oncol 30: 3093-3099, 2012
19. Mak V, Hamm J, Chhanabhai M, et al: Survival of patients with peripheral T-cell lymphoma after first relapse or progression: Spectrum of disease and rare long-term survivors. J Clin Oncol 31:1970-1976, 2013

20. Parrilla Castellar ER, Jaffe ES, Said JW, et al: ALK-negative anaplastic large cell lymphoma is a genetically heterogeneous disease with widely disparate clinical outcomes. Blood 124:1473-1480, 2014

21. Feldman $A L$, Law $M$, Remstein $E D$, et al: Recurrent translocations involving the IRF4 oncogene locus in peripheral T-cell lymphomas. Leukemia 23:574-580, 2009

22. Wang $T$, Feldman $A L$, Wada $D A$, et al: GATA-3 expression identifies a high-risk subset of PTCL, NOS with distinct molecular and clinical features. Blood 123:3007-3015, 2014

23. Wilcox RA: A three-signal model of T-cell lymphoma pathogenesis. Am J Hematol 91:113-122, 2016

24. Sandell RF, Boddicker RL, Feldman AL: Genetic landscape and classification of peripheral $T$ cell lymphomas. Curr Oncol Rep 19:28, 2017

25. Maurer MJ, Jais JP, Ghesquières $H$, et al: Personalized risk prediction for event-free survival at 24 months in patients with diffuse large B-cell lymphoma. Am J Hematol 91:179-184, 2016

26. Jakobsen LH, Bøgsted $M$, Brown PN, et al: Minimal loss of lifetime for patients with diffuse large B-cell lymphoma in remission and event free 24 months after treatment: A Danish population-based study. J Clin Oncol 35:778-784, 2017

27. Novak AJ, Asmann YW, Maurer MJ, et al: Whole-exome analysis reveals novel somatic genomic alterations associated with outcome in immunochemotherapy-treated diffuse large B-cell lymphoma. Blood Cancer J 5:e346, 2015

\section{Affiliations}

Matthew J. Maurer, N. Nora Bennani, Stephen M. Ansell, James R. Cerhan, and Andrew L. Feldman, Mayo Clinic, Rochester, MN; Fredrik Ellin, Kalmar County Hospital, Kalmar; Fredrik Ellin and Thomas Relander, Lund University; Mats Jerkeman and Thomas Relander, Skåne University Hospital, Lund; Karin E. Smedby, Karolinska Institutet and Karolinska University Hospital, Stockholm, Sweden; Line Srour, Joseph M. Connors, Graham W. Slack, and Kerry J. Savage, Centre for Lymphoid Cancer, BC Cancer Agency, Vancouver, British Columbia, Canada; and Brian K. Link, University of Iowa Hospitals and Clinics, Iowa City, IA.

\section{Support}

Supported by Grants No. P50 CA97274 (University of Iowa/Mayo Clinic Lymphoma Specialized Programs of Research Excellence), R01 CA177734 (to A.L.F.), P30 CA15083 (Mayo Clinic Cancer Center), and U01 CA195568 (Lymphoma Epidemiology of Outcomes Cohort) from the National Cancer Institute and by the Terry Fox Research Institute and the British Columbia Cancer Foundation (BC Cancer Agency).

\section{Prior Presentation}

Presented in part at the 57th Annual Meeting of the American Society of Hematology, Orlando, FL, December 5-8, 2015, and the 58th Annual Meeting of the American Society of Hematology, San Diego, CA, December 3-6, 2016. 


\section{AUTHORS' DISCLOSURES OF POTENTIAL CONFLICTS OF INTEREST}

International Assessment of Event-Free Survival at 24 Months and Subsequent Survival in Peripheral T-Cell Lymphoma

The following represents disclosure information provided by authors of this manuscript. All relationships are considered compensated. Relationships are self-held unless noted. I = Immediate Family Member, Inst = My Institution. Relationships may not relate to the subject matter of this manuscript. For more information about ASCO's conflict of interest policy, please refer to www.asco.org/rwc or ascopubs.org/jco/site/ifc.

Matthew J. Maurer

Research Funding: Kite Pharma (Inst), Celgene (Inst)

Fredrik Ellin

Consulting or Advisory Role: CTI Life Sciences

\section{Line Srour}

No relationship to disclose

\section{Mats Jerkeman}

Research Funding: Janssen, Celgene, Abbot, Gilead

N. Nora Bennani

Research Funding: Bristol-Myers Squibb Brazil (Inst)

Travel, Accommodations, Expenses: Celgene

\section{Joseph M. Connors}

Research Funding: Seattle Genetics (Inst), Bristol-Myers Squibb (Inst), Amgen (Inst), Bayer Health (Inst), Cephalon (Inst), Roche (Inst), Genentech (Inst), Janssen Oncology (Inst), Eli Lilly (Inst), Merck (Inst), NanoString Technologies (Inst), Takeda (Inst)

Patents, Royalties, Other Intellectual Property: Evaluation of mantle-cell lymphoma and methods related thereof (Inst), Methods for selecting and treating lymphoma types (Inst)

\section{Graham W. Slack}

Consulting or Advisory Role: Seattle Genetics

Karin E. Smedby

Consulting or Advisory Role: Celgene

Research Funding: Janssen
Stephen M. Ansell

Honoraria: WebMD, Research to Practice

Research Funding: Bristol-Myers Squibb (Inst), Celldex (Inst), Seattle Genetics (Inst), Merck (Inst), Affimed Therapeutics (Inst), Trillium Therapeutics (Inst)

Brian K. Link

Consulting or Advisory Role: Genentech, Abbvie, Gilead Sciences, Celgene

Research Funding: Genentech (Inst)

Travel, Accommodations, Expenses: Genentech, Celgene

James R. Cerhan

Consulting or Advisory Role: Janssen, Gilead Sciences

Research Funding: Kite Pharma (Inst)

Thomas Relander

No relationship to disclose

Kerry J. Savage

Honoraria: Seattle Genetics, Bristol-Myers Squibb, Merck, Novartis, Gilead Sciences, Abbvie, Takeda

Consulting or Advisory Role: Seattle Genetics, Bristol-Myers Squibb, Merck, Servier, Novartis, Gilead Sciences

Speakers' Bureau: Seattle Genetics

Research Funding: Roche (Inst)

Andrew L. Feldman

Consulting or Advisory Role: Infinity Pharmaceuticals

Patents, Royalties, Other Intellectual Property: Inventor of technology for which Mayo Clinic holds an unlicensed patent or has submitted a patent application (Inst) 


\section{Appendix}

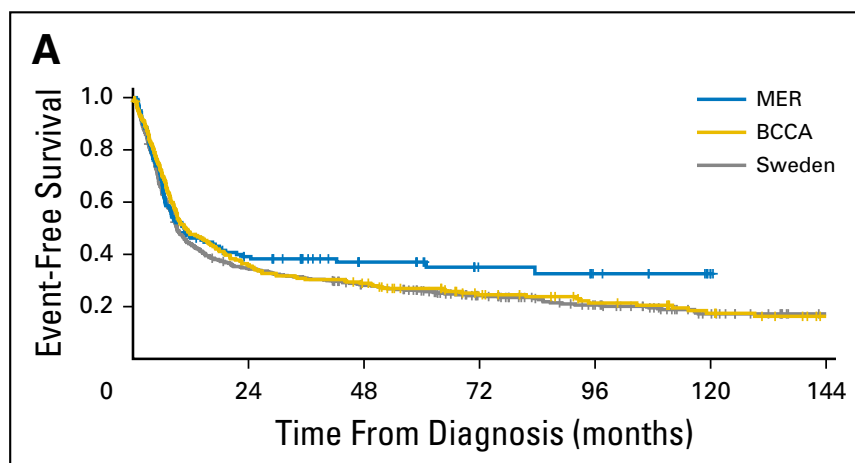

\section{B}

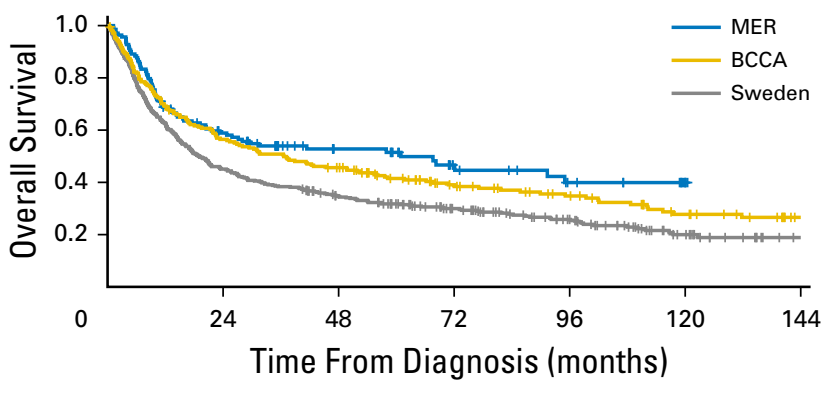

No. at risk:

$\begin{array}{lcccccc}\text { MER } & 138 & 46 & 25 & 14 & 10 & 2 \\ \text { BCCA } & 215 & 77 & 60 & 38 & 26 & 17 \\ \text { Sweden } & 417 & 141 & 107 & 71 & 44 & 19\end{array}$

No. at risk:

$\begin{array}{lcccccc}\text { MER } & 138 & 73 & 40 & 23 & 14 & 3 \\ \text { BCCA } & 215 & 120 & 95 & 60 & 45 & 29 \\ \text { Sweden } & 417 & 188 & 133 & 91 & 57 & 23\end{array}$

Fig A1. Event-free survival (A) and overall survival (B) in patients with peripheral T-cell lymphoma by cohort. BCCA, British Columbia Cancer Agency; MER, Molecular Epidemiology Resource.
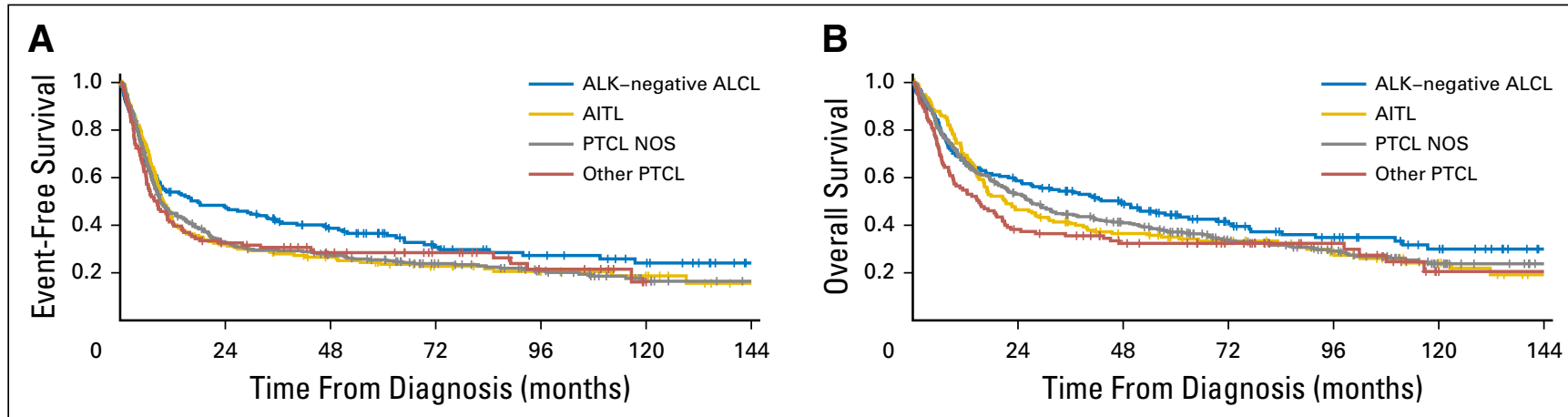

No. at risk:

No. at risk:

\begin{tabular}{|c|c|c|c|c|c|c|c|c|c|c|c|c|c|}
\hline ALK-negative ALCL & 165 & 77 & 54 & 30 & 21 & 14 & ALK-negative ALCL & 165 & 95 & 69 & 40 & 28 & 17 \\
\hline AITL & 158 & 50 & 36 & 24 & 17 & 9 & AITL & 158 & 73 & 50 & 34 & 22 & 12 \\
\hline PTCL, NOS & 332 & 102 & 77 & 52 & 34 & 14 & PTCL, NOS & 332 & 170 & 119 & 78 & 53 & 24 \\
\hline Other PTCL & 115 & 35 & 25 & 17 & 8 & 1 & Other PTCL & 115 & 43 & 30 & 22 & 13 & 2 \\
\hline
\end{tabular}

Fig A2. Event-free survival (A) and overall survival (B) in patients with peripheral T-cell lymphoma (PTCL) by subtype. AITL, angioimmunoblastic T-cell lymphoma; $A$ LCL, anaplastic large-cell lymphoma; ALK, anaplastic lymphoma kinase; NOS, not otherwise specified. 


\section{A}

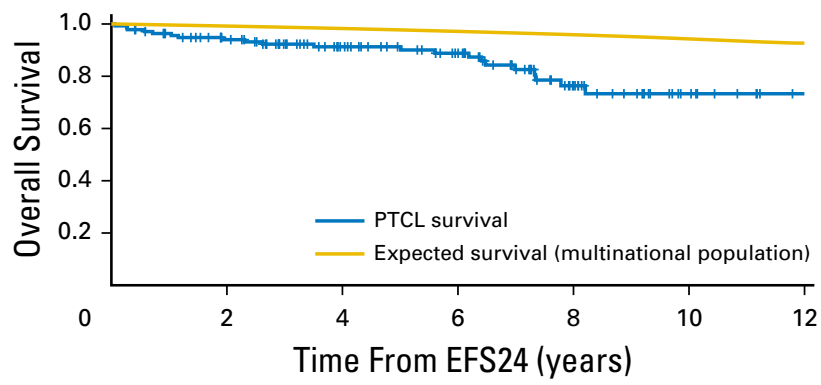

$\begin{array}{lllllll}\text { No. at risk: } & 137 & 114 & 84 & 66 & 31 & 11\end{array}$
B

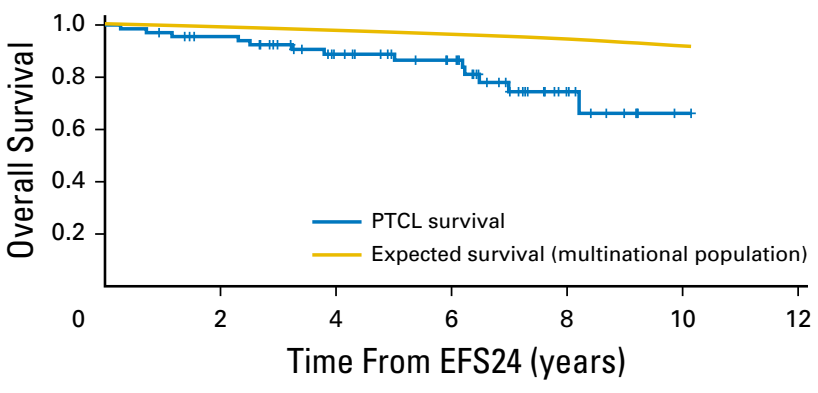

No. at risk: 68

61

45

35

11

Fig A3. Overall survival after achieving 24-month event-free survival (EFS24) in (A) patients age $\leq 60$ years and (B) patients receiving autologous stem-cell transplantation in first remission. PTCL, peripheral T-cell lymphoma.

\begin{tabular}{|c|c|c|c|c|c|c|c|c|c|c|c|}
\hline \multirow[b]{2}{*}{$\begin{array}{l}\text { EFS Time } \\
\text { Point }\end{array}$} & \multicolumn{2}{|c|}{ At Time Point } & \multicolumn{3}{|c|}{3 Years From Time Point } & \multicolumn{3}{|c|}{5 Years From Time Point } & \multicolumn{3}{|c|}{7 Years From Time Point } \\
\hline & $\begin{array}{c}\text { No. of } \\
\text { Patients }\end{array}$ & $\begin{array}{c}\text { SMR } \\
(95 \% \mathrm{Cl})\end{array}$ & $\begin{array}{l}\text { No. of } \\
\text { Patients } \\
\text { at Risk }\end{array}$ & $\begin{array}{c}\% \\
\text { Alive }\end{array}$ & $\begin{array}{c}\% \text { Expected } \\
\text { per } \\
\text { Population }\end{array}$ & $\begin{array}{c}\text { No. of } \\
\text { Patients at } \\
\text { Risk }\end{array}$ & $\begin{array}{c}\% \\
\text { Alive }\end{array}$ & $\begin{array}{c}\text { \% Expected } \\
\text { per } \\
\text { Population }\end{array}$ & $\begin{array}{c}\text { No. of } \\
\text { Patients at } \\
\text { Risk }\end{array}$ & $\begin{array}{c}\% \\
\text { Alive }\end{array}$ & $\begin{array}{c}\text { \% Expected } \\
\text { per } \\
\text { Population }\end{array}$ \\
\hline 12 months & 344 & 4.50 (3.80 to 5.33$)$ & 222 & 75.0 & 95.1 & 147 & 67.3 & 91.7 & 101 & 60.9 & 88.5 \\
\hline 18 months & 297 & 3.67 (3.00 to 4.49$)$ & 201 & 80.4 & 95.1 & 133 & 74.9 & 91.7 & 84 & 63.7 & 88.4 \\
\hline 24 months & 264 & 3.16 (2.48 to 3.98 & 180 & 85.0 & 95.0 & 119 & 78.4 & 91.6 & 74 & 67.8 & 88.2 \\
\hline 30 months & 242 & 2.77 (2.13 to 3.59$)$ & 157 & 87.9 & 94.9 & 109 & 80.0 & 91.5 & 55 & 67.0 & 88.1 \\
\hline 36 months & 226 & 2.72 (2.06 to 3.59$)$ & 135 & 87.7 & 94.8 & 94 & 80.2 & 91.3 & 43 & 65.3 & 87.9 \\
\hline 48 months & 192 & 2.54 (1.84 to 3.51$)$ & 113 & 90.4 & 94.7 & 70 & 78.4 & 91.1 & 28 & 65.1 & 87.7 \\
\hline 60 months & 162 & 2.61 (1.80 to 3.77 ) & 90 & 89.9 & 94.7 & 40 & 72.5 & 91.1 & 15 & 70.0 & 87.3 \\
\hline
\end{tabular}

Abbreviations: EFS, event-free survival; SMR, standardized mortality ratio.

\begin{tabular}{|c|c|c|c|c|c|c|c|c|c|c|c|}
\hline \multirow[b]{2}{*}{ Time Point } & \multicolumn{2}{|c|}{ At Progression } & \multicolumn{3}{|c|}{3 Years From Time Point } & \multicolumn{3}{|c|}{5 Years From Time Point } & \multicolumn{3}{|c|}{7 Years From Time Point } \\
\hline & $\begin{array}{c}\text { No. } \\
\text { of Patients }\end{array}$ & $\begin{array}{c}\text { SMR } \\
(95 \% \mathrm{Cl})\end{array}$ & $\begin{array}{c}\text { No. of } \\
\text { Patients } \\
\text { at Risk }\end{array}$ & $\%$ Alive & $\begin{array}{l}\% \text { Expected } \\
\text { per Population }\end{array}$ & $\begin{array}{c}\text { No. of } \\
\text { Patients } \\
\text { at Risk }\end{array}$ & $\%$ Alive & $\begin{array}{c}\% \text { Expected } \\
\text { per Population }\end{array}$ & $\begin{array}{l}\text { No. of } \\
\text { Patients at Risk }\end{array}$ & $\%$ Alive & $\begin{array}{c}\% \text { Expected } \\
\text { per Population }\end{array}$ \\
\hline 12 months & 334 & 47.1 (42.1 to 52.3 ) & 47 & 15.2 & 95.8 & 28 & 10.6 & 92.8 & 16 & 7.4 & 90.6 \\
\hline 18 months & 377 & 45.2 (40.6 to 50.3 ) & 54 & 15.7 & 95.5 & 30 & 10.9 & 92.9 & 17 & 7.9 & 90.7 \\
\hline 24 months & 401 & 44.4 (40.1 to 49.3$)$ & 58 & 16.2 & 95.4 & 32 & 11.5 & 92.8 & 18 & 8.1 & 90.6 \\
\hline 30 months & 418 & 43.8 (39.4 to 48.5$)$ & 62 & 16.6 & 95.5 & 35 & 12.0 & 92.9 & 21 & 8.8 & 90.8 \\
\hline 36 months & 425 & 43.2 (39.1 to 47.8 ) & 65 & 17.0 & 95.5 & 36 & 12.2 & 93.0 & 21 & 8.9 & 90.8 \\
\hline 48 months & 433 & 42.6 (38.5 to 47.1$)$ & 67 & 17.1 & 95.5 & 37 & 12.4 & 93.0 & 22 & 9.1 & 90.9 \\
\hline 60 months & 445 & 40.1 (36.3 to 44.3 ) & 72 & 17.9 & 95.3 & 39 & 12.8 & 92.7 & 23 & 9.3 & 90.6 \\
\hline
\end{tabular}

